\title{
The Practice Research of Blended Learning in Modern Educational Technology
}

\begin{abstract}
Wang Zhou-xiu
Nantong University, Jiangsu, China

This study makes Modern Educational Technology in colleges and universities as a teaching case based on the platform of Blackboard. It also discusses the application of specific teaching practice of reflecting the course features in the module of blended learning. Concretely, this paper will construct the module of blended learning based on the Blackboard platform through analyzing the design requirement of blended learning in the compulsory course-Modern Educational Technology in normal universities, and state the practice of blended learning based on the Blackboard from the aspects of learning content, learning organization, and learning evaluation.
\end{abstract}

Keywords: Blackboard, blended learning, learning model, teaching practice

\section{Introduction}

The research of blended learning has been long-standing. The understandings of blended learning are different from different researchers (Bersin, 2016). Curtis J. Bonk (2009) believed that the blended learning was the combination of face-to-face teaching and computer supported learning. He Kekang (2004) indicated the alleged blending learning was to tie the advantage of traditional methods of learning in e-learning (digital and network learning). That is to say, it should not only exert the principal role of teachers to guide, inspire, and monitor the teaching process, but also fully embody the initiative, enthusiasm, and creativity of students who are the fundamental part of learning. Zou Jinping (2014), a researcher from Taiwan, pointed out that blended learning was the teaching method that teachers or course units flexibly select entities of the classroom and synchronous or asynchronous mode on the basis of teaching needs in curriculum. Although different researchers hold different statements of blended learning, they generally believe that blended learning is the combination of network learning and traditional classroom learning and complement each other. The blending learning plays the leading role of teachers in the classroom and reflects the function of students as the main part.

In early time, blended learning based on Internet research in China was mainly for distance learners or corporate training staff, rather than students in school. With the advancement of informationized process in higher education, the continuous development of digital campus construction, and improvement of domestic network bandwidth in colleges and universities, utilizing the network technology to assist revolution of teaching organization form has been regarded as an important method to improve the quality of teaching in colleges and universities. At present, more than $70 \%$ of universities have already started using the network teaching management platform, such as Skyclass, Blackboard, etc., in order to support a blending teaching of

\footnotetext{
* Acknowledgment: This paper was sponsor supported by Modern Educational Technology Research Project of Jiangsu Province (No. 2015-R-40624).

Wang Zhou-xiu, M.A., associate professor, Department of Education Technology, Nantong University.
} 
full-time students at schools. As follow, we will connect the Modern Educational Technology to explore the model of blended learning based on Blackboard.

\section{The Design of Blended Learning Model in Modern Educational Technology Based on Blackboard}

\section{Blackboard Platform}

Blackboard is an Internet teaching management platform centering on courses. Teachers can build their own courses and give lessons through the Internet. What is more, students can spontaneously browse, select, and take courses. Each course possesses independent learning area, communication area, test area, and supervision area. Activities, such as tutorship, exchange discussion, and jointly course learning, can be done between teachers and students, teaching assistants and students and among members of learning groups. These characteristics accord with blended learning and give perfect support to it. In other words, Blackboard is the Internet teaching platform providing technology supports. Blended learning, as a comprehended teaching strategy, can deliver teaching content, conduct learning activities by this platform and provide theoretical guide. It is enhanced to combine Blackboard and blended learning to present teaching contents and learning sources, and promote learning effectively.

\section{The Necessity of Blended Learning in Modern Educational Technology}

Modern Educational Technology is a compulsory course for students in normal universities. This course combines theory with application and bonds technology to practice. Its content relates to modern media technology application, informationized teaching design, multi-media teaching resources design and development, and teachers' professional improvement in the information age. However, this course has been limited for only 36 credit hours despite of the complexity and the rapid update of the contents. Moreover, only a large classroom can meet the demand of the course, because it is compulsory and all the students have to take this course. Because of the amount of students with different levels in information technology skills, it is difficult for teachers to have effective communication with each student in class or after class. Therefore, learning online takes many advantages, such as rich multi-media resources, fast update, diverse communication channel, and learning self-independence. With this background, the online course-Modern Educational Technology based on Blackboard, combining classroom teaching with online learning tightly, will improve the limited class times, the irrelevance of teaching strategy and reality, singleness of learning and assessment, lacking of individuation and communication between teachers and students, and evaluate students' learning and experience in every level.

\section{The Structure of Blended Learning Pattern of Modern Educational Technology}

The blended learning pattern is a way to present the process of blended learning clearly and clarify blended learning in various parts (Giannousi, Vernadakis, \& Derri, 2014). There are several patterns. Purnima Valiathan (2002) presented the skill-driven pattern, attitude-driven pattern, and ability-driven pattern. Barnum and Paarmann (2002) raised four stages of blended learning: web-based transmission, face-to-face processing, forming certain products, and extending cooperative learning. According to the principles of teaching design, the traits of Blackboard, and the contents of Modern Educational Technology, the pattern of blended learning consists of learning content design, blended learning design, and diverse assessment design. It can be specifically shown in Figure 1. 


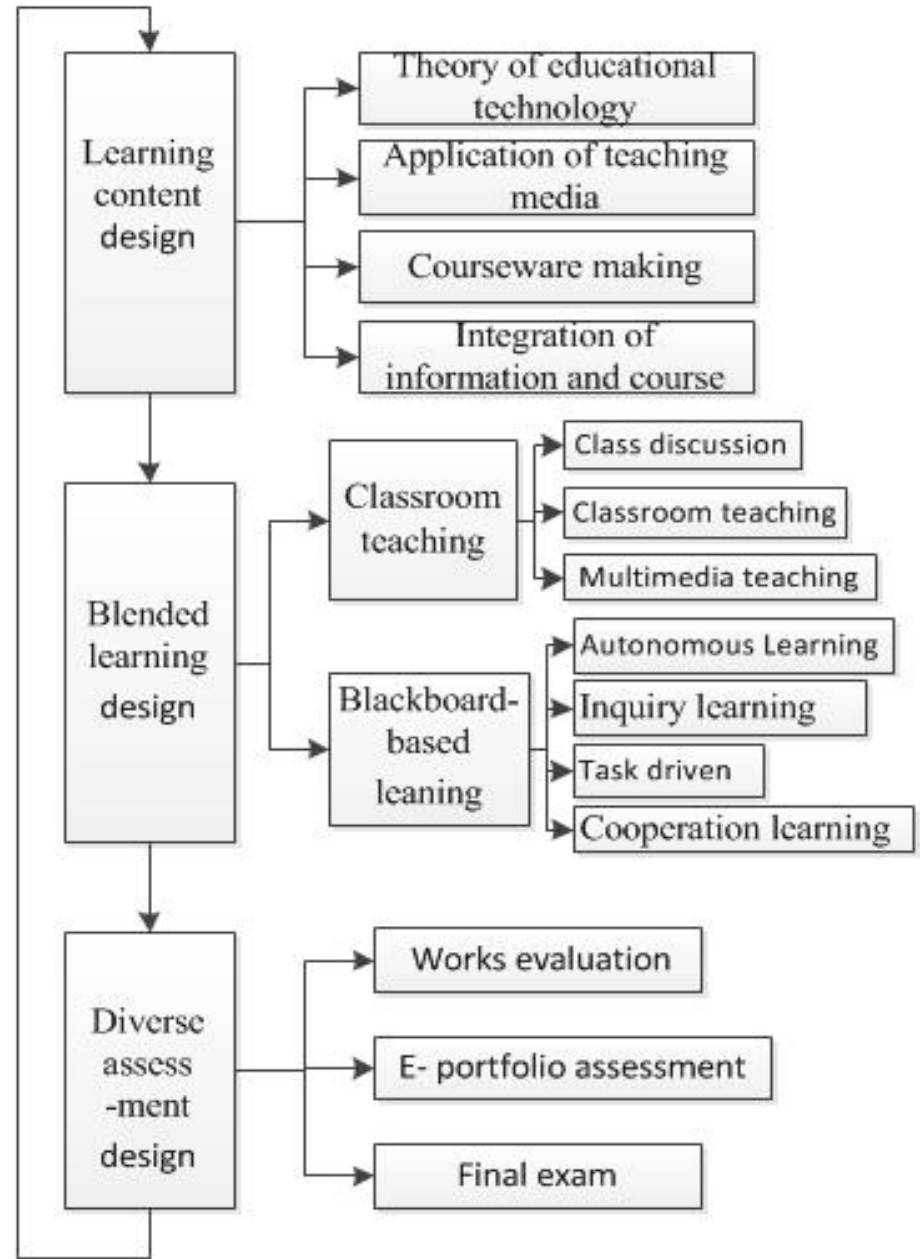

Figure 1. Implementation flow chart of blended learning.

Learning content design. The main content of Modern Educational Technology in Nantong University contains educational technology theory, teaching media application, PowerPoint-making, and integration of information technology course, as a result of studying the National Educational Technology Standards, Curriculum Reform of Elementary Education, integration of information technology course, and continuous learning and research ability of educational technology. Furthermore, it has considered educational technology knowledge and the realistic need in elementary education integrating educational technology. Among the rest, educational technology theory leads the designing, making, using, and teaching in the other three parts. Through media, PowerPoint-making acts on the practice of integrating information with the course, which is the core and main goal of Modern Educational Technology.

Blended learning design. The learning activities consist of classroom teaching activities and Blackboard-based learning and communication. Through utilizing media in classroom teaching, teachers demonstrate PowerPoint, illustrates basic knowledge in detail, build problem scenario, apply multi-learning theory, and communicate with students to solve problems.

Blackboard-based learning and communication essentially consists of topics of Internet learning and activity design, which is the central part of blended learning. Blended learning based on Blackboard follows two key rules. The first rule is learner-centered, which means considering learners' learning need, habits, 
current ability, cognition traits, and learning goals. The second rule is the suited learning content, which means different learning content matching different learning style. Following these two rules, this course is designed for three Internet learning subjects conducting blended learning: Educational Technology and Teacher's Professional Development, Informationized Teaching and Assessment, and Application of New Technology in Education. Each subject consists of learning goals, learning tasks, learning suggestions, learning activities, and learning resources. Students' main learning activities on Blackboard are online learning materials reading, independent inquiry learning, group cooperation learning, online discussion, resources sharing, and assessment and reflection. With the teacher's guide, every student learns on the Internet independently, communicate, finish assignments, and submit to the Internet platform.

Diverse assessment. The ultimate learning goal of this course is to foster students' educational technology, independent learning, cooperation, and innovation ability in normal universities. The guiding ideology of blended learning is to transfer from assessing knowledge to improve learning ability and literacy. Therefore, this course is the diverse assessment, applying electronic portfolio, group work assessment, interactive assessment, teachers' assessment, learner assessment, group assessment, and multi-entity diverse assessment based on the Blackboard platform. All the diagnostic assessment, formative assessment, and summative assessment penetrate the whole blended learning process, in order to fully inspect students' learning and educational technology ability.

\section{The Practice Analysis of Blended Learning of Modern Educational Technology Based on Blackboard}

According to the process of this blended learning course constructed before, the practice of this course on the Blackboard platform of Nantong University has been regulated. For the purpose of conducting the practice, more than 200 students in Nantong university have been involved as the volunteers who enrolled in 2016 from the following normal majors: PE, English, and Geography, etc.. From learners' perspective, the process of this blended learning course comprises three portions, which are classroom learning of "teacher-leading and student-principal," online learning of "students-principal and teacher-supporting," and skill practice and multi-assessment. During the course, there are learners-trait-analysis, teaching objective and plan-making, environment designing, resources developing, learning activity designing, and learning assessment. Combining information technology with professional pedagogy of all the majors and emphasizing subject-pedagogy design under the information technology have been paid the most attention that reflects the application of new technology in education.

After the practice, investigation and analysis have been completed from the aspects of students' learning, evaluation, and feedback through questionnaire, work check, and interview.

\section{Questionnaire}

The questionnaire was designed for the attitude of students' participation in blended learning. There were 305 questionnaires delivered and 299 received that the receiving rate was $98 \%$ with 287 questionnaires being valid that the valid rate was $96 \%$. As it can be seen from the consequence, more than $95 \%$ students enjoy this approach of blended learning after one semester's learning and regard it greatly helpful. For instance, as been asked, "What extend you think blended learning helpful in mastering knowledge and skill?" "Great," "Much,” “A little," "Little," or "No.” Many students select "Great," 85\% students think discussing board usefully in 
theoretical learning, and $80 \%$ students think extensive learning materials helpfully in theoretical learning. Seventy percent students reflect the PowerPoint-making software delivered by teachers that is useful.

\section{Assignments}

From the students' assignments, the noticeable improvement can be told between students of blended learning and previous students. The major differences are as follows. The PowerPoint presents the applying value of multi-media in creating teaching scenario, promoting cognition, and developing thinking in senior and junior classroom. The artistic level has risen by more coordinate and beautiful appearances. These results are accords to several reasons. Teachers put more effort to preparation in course video, materials, and cases of PowerPoint. More self-learning of conducting the skills of courseware-making can be done by students. Teachers could put more consideration to guide PowerPoint-making in class.

\section{Interview}

Students reflect that blended learning provides freedom. They can arrange learning time without restriction and make appropriate learning plan. When a problem is unsolved in classroom, they can think independently and solve it by various learning resources on the platform. Students also feedback that it has appropriate to use discussion when learning theory, for it will mobilize enthusiasm and show respectable effect. In addition, the cases and particular videos offered by teachers, which are visualized, intuitional, and more controllable after processed, were largely popular in students who have different experience and acceptance capability. It shows in the interview that students expect that blended learning can be adopted in other courses.

In summary, blended learning based on Blackboard has much improvement in promoting student motivation, learning efficiency, and teaching effect in comparison with traditional teaching.

\section{Conclusion}

This paper clarifies teaching mode of blended learning based on Blackboard by the case study in Nantong University. In this mode, the relations of teachers and students have changed to "teacher-leading and student-principal," which foster students' ability on independent learning and practice, and promote students' information literacy. In implementing blended learning mode, considering students' learning need and teachers' pedagogy need and paying attention to teacher's feeling should be considered with this mode. It is a beneficial trial of this study applying blended learning based on Blackboard to Modern Educational Technology. Further study and practice need to be done in regard of the researcher's limited time, capability, and superficial understanding of certain problems.

\section{References}

Barnum, C., \& Paarmann, W. (2002). Bringing introduction to the teacher: A blended learning model. T.H.E Journal, 30(2), 56-64.

Bersin, J. (2016). The blended learning book: Best practices proven methodologies and lessons learned. Turkish Online Journal of Distance Education, 11(3), 1-9.

Bonk, C. J. (2009). The world is open: How web technology is revolutionizing education. New York, N.Y.: John Wiley \& Sons.

Giannousi, M., Vernadakis, N., \& Derri, V. (2014). A comparison of student knowledge between traditional and blended instruction in a physical education in early childhood course. Turkish Online Journal of Distance Education, 15(1), 99-113.

He, K. K. (2004). New development of theory of educational technology from blending learning. E-Education Research, 3, 37-48. Purnima, V. (2002). Blended learning models. Retrieved September 28, 2006, from http://www.learningcircuits.org

Zou, J. P. (2014). Model of blended learning basic blue. Retrieved September 21, 2006, from http://www.blog.online-edu.org/ goldred/001658. htm 